\title{
Urinary Excretion of Acid Muco-polysaccharide in Sibs with Morquio's Syndrome and Reilly's Granules in Leucocytes
}

\author{
N. MATSANIOTIS ${ }^{\star}$, C. KATTAMIS, H. LEHMANN, and D. H. ORRELL \\ From the Paediatric Clinic of Athens University and the Biochemical Section of the John Bonnett \\ Clinical Laboratories, Addenbrooke's Hospital, Cambridge
}

It is likely that Hurler's syndrome, Morquio's syndrome, and the Morquio-Ullrich syndrome result from inborn errors of muco-polysaccharide metabolism. The classification of the three groups on the basis of purely clinical criteria may be superseded when more information is available about the basic biochemical lesions. It is current practice (Nelson, 1964) to call those cases with the characteristic facial appearance of gargoyles, mental retardation, hepatosplenomegaly, skeletal changes, and corneal opacities, Hurler's syndrome; those cases with the characteristic skeletal and epiphysial changes alone, Morquio's syndrome; and those cases with the features of Morquio's syndrome together with some additional feature such as mental retardation, corneal opacities, or hepatosplenomegaly, Morquio-Ullrich syndrome. Differences of opinion have arisen as to the place in this classification of those cases of Morquio's syndrome that are complicated only by the presence of Reilly's granules in the polymorphonuclear leucocytes, these having been originally described in cases of Hurler's syndrome (gargoylism) (Reilly, 1941).

The finding of excessive amounts of acid-mucopolysaccharides (AMPS) in the urine and tissues of cases of Hurler's syndrome stimulated the investigation of AMPS excretion in the urine of cases of the other two syndromes (Clausen, Dyggve, and Melchior, 1963). We report the clinical features together with the results of the determination of the amounts of AMPS in 24-hour samples of urine, from two sibs presenting at the Paediatric Clinic of Athens University with apparently uncomplicated Morquio's syndrome showing Reilly's granules in the leucocytes.

\section{Case Reports}

Case 1. A hitherto normal female child showed some retardation of growth and difficulty in walking at

Received February 8, 1967.

$\star$ Present address: Aghia Sophia Hospital, Athens 609, Greece. the age of 2 ; she presented at the age of 5 when she was of short stature $(89 \mathrm{~cm}$.) and showed the characteristic appearances of Morquio's syndrome with thoracic kyphosis, large antero-posterior diameter of the chest, and genu valgum. The joints were excessively mobile. The liver was palpable $2 \mathrm{~cm}$. below the costal margin on the right, but there were no other abnormal physical signs.

Skeletal radiographs showed flattening of the vertebral bodies with 'beaking' anteriorly, irregular endochondral ossification in the major epiphyses, and coarsening of the trabeculae in the metacarpal bones.

Reilly's granules were present in $10 \%$ of the neutrophil polymorphs in the peripheral blood.

Case 2. A male child presented at the age of 18 months with slight kyphosis of the thoracic spine which had been present for 6 months; there was large anteroposterior diameter of the chest, genu valgum, liver palpable $2 \mathrm{~cm}$. below the right costal margin, and a soft apical systolic murmur, without any cther abnormal physical signs.

Skeletal radiographs showed flattening of the vertebral bodies with irregular ossification in the femoral heads.

Reilly's granules were present in $8 \%$ of the neutrophils in the peripheral blood.

Both cases were seen again after $2 \frac{1}{2}$ years, when the clinical features in Case 1 were unchanged, whereas those in Case 2 were more conspicuous in that the boy was short ( $82 \mathrm{~cm}$. at 4 years) with more severe deformity of the chest and legs.

The parents are not blood relations, and there are no other sibs.

\section{Material and Methods}

The $p \mathrm{H}$ of $100 \mathrm{ml}$. aliquots of 24-hour collections of urine was adjusted to 5.0 by adding $2 \mathrm{~N} \mathrm{HCl}$. The AMPS were then precipitated by adding $0.4 \mathrm{ml} .20 \%$ solution of cetyl trimethyl ammonium bromide (CTAB), and leaving to stand for 24 hours at $4^{\circ} \mathrm{C}$. The precipitate was washed three times in absolute alcohol and redissolved in $50 \mathrm{ml} .10 \%$ solution of sodium acetate and the $p \mathrm{H}$ adjusted to 9.0 by adding $5 \mathrm{~N} \mathrm{NaOH}$. The solution was filtered and the AMPS reprecipitated by 
adding $250 \mathrm{ml}$. absolute alcohol and leaving to stand for a further 24 hours. This precipitate was redissolved in $25 \mathrm{ml}$. distilled water. To $1 \mathrm{ml}$. aliquots of the aqueous solution were added $6 \mathrm{ml} .85 \%$ sulphuric acid and the mixture heated on a boiling water bath for 30 minutes. After cooling, $0.2 \mathrm{ml}$. freshly prepared $0.1 \%$ alcoholic carbazole (B.D.H. Ltd.) were added and absorption of the product was measured at $530 \mathrm{~m} \mu$ in the S.P. 500 spectrophotometer. This was compared with that of standards containing glucuronic acid against a blank containing distilled water instead of the $1 \mathrm{ml}$. aliquot of extracted AMPS.

\section{Results}

In Case 1 (at the age of 5 years) the level of AMPS was $3.4 \mathrm{mg} . / 24 \mathrm{hr}$; and in Case 2 (at the age of 18 months) the AMPS was $1.6 \mathrm{mg} . / 24 \mathrm{hr}$. Both these results fall within the normal range found by Teller, Burke, Rosevear, and McKenzie (1962), using a similar technique.

\section{Discussion}

Raised urine concentrations of AMPS have been demonstrated in cases of Hurler's syndrome (DiFerrante and Rich, 1956; Meyer, Grumbach, Linker, and Hoffman, 1958), using the technique of CTAB precipitation and estimation of the glucuronic acid content of the hydrolysed precipitate by the alcoholic carbazole reaction (Dische, 1947). This increase has been shown to be due to raised concentrations of chondroitin sulphate $B$ and heparitin sulphate, the concentrations of chondroitin sulphates A and C being normal (Meyer, Davidson, Linker, and Hoffman, 1956; Meyer et al., 1958; Meyer, Hoffman, Linker, Grumbach, and Sampson, 1959).

The 24-hour excretion of AMPS in normal children has been measured using both benzidine hydrochloride as a precipitating agent (Kerby, 1954) and CTAB (Teller et al., 1962), the former noting slightly higher values in males, the latter failing to confirm this but noting a slight rise with age.

The 24-hour excretion rates of AMPS in children with Hurler's syndrome has likewise been shown to be raised (Teller et al., 1962). The 24-hour excretion rates in one of each of two pairs of children with Morquio's syndrome associated with the presence of Reilly's granules, were raised, but were normal in the other two (Zellweger, Ponseti, Pedrini, Stamler, and Von Noorden, 1961; Robins, Stevens, and Linker, 1963). Two cases have been described with the skeletal changes of Morquio's syndrome, associated with deafness, and with the presence of azurophilic granules in the reticulum cells of the bone-marrow. One of these children had a raised 24-hour excretion of AMPS, the other being within the normal range (Sanfilippo and Good, 1962).

Our two cases present the features of Morquio's syndrome associated with Reilly's granules in some of the polymorphs. The 24-hour AMPS excretion in the urine in both cases was within normal limits when estimated as the amount of glucuronic acid released by hydrolysis with concentrated sulphuric acid.

\section{Summary}

The 24-hour urinary excretion rate of acid mucopolysaccharides was measured in two cases of Morquio's syndrome associated with Reilly granules in the cytoplasm of some of the polymorphonuclear leucocytes in the peripheral blood. The technique used was that of precipitation by cetyl trimethyl ammonium bromide, acid hydrolysis, and estimation of the freed glucuronic acid by the alcoholic carbazole reaction. The results in both cases fell within the normal limits found by Teller et al. (1962).

\section{REFERENCES}

Clausen, J., Dyggve, H. V., and Melchior, J. C. (1963). Mucopolysaccharidosis. Paper electrophoretic and infra-red analysis of the urine in gargoylism and Morquio-Ullrich's disease. Arch. Dis. Childh., 38, 364.

DiFerrante, N., and Rich, C. (1956). The determination of acid aminopolysaccharide in urine. F. Lab. clin. Med., 48, 491.

Dische, Z. (1947). A new specific color reaction of hexuronic acids. F. biol. Chem., 167, 189.

Kerby, G. P. (1954). The excretion of glucuronic acid and of acid mucopolysaccharides in normal human urine. $\mathcal{F}$. clin. Invest., 33, 1168.

Meyer, K., Davidson, E., Linker, A., and Hoffman, P. (1956). The acid mucopolysaccharides of connective tissue. Biochim. biophys. Acta (Amst.), 21, 506.

—-, Grumbach, M. M., Linker, A., and Hoffman, P. (1958). Excretion of sulfated mucopolysaccharides in gargoylism. Proc. Soc. exp. Biol. (N.Y.), 97, 275.

-, Hoffman, P., Linker, A., Grumbach, M. M., and Sampson, P. (1959). Sulfated mucopolysaccharides of urine and organs in gargoylism (Hurler's syndrome). II. Additional studies. ibid., 102, 587.

Nelson, W. E. (1964). Textbook of Pediatrics, 8th ed., p. 1358. Saunders, Philadelphia.

Reilly, W. A. (1941). The granules in the leukocytes in gargoylism. Amer. F. Dis. Child., 62, 489.

Robins, M. M., Stevens, H. F., and Linker, A. (1963). Morquio's disease: an abnormality of mucopolysaccharide metabolism. F. Pediat., 62, 881 .

Sanfilippo, S. J., and Good, R. J. (1962). Urinary acid mucopolysaccharides (AMP) in the Hurler syndrome and Morquio's disease. ibid., 61, 296.

Teller, W. M., Burke, E. C., Rosevear, J. W., and McKenzie, B. F. (1962). Urinary excretion of acid mucopolysaccharides in normal children and patients with gargoylism. $\mathcal{f}$. Lab. clin. Med., 59, 95.

Zellweger, H., Ponseti, I. V., Pedrini, V., Stamler, F. S., and Von Noorden, G. K. (1961). Morquio-Ullrich's disease: report of 2 cases. F. Pediat., 59, 549. 